\title{
The University's Governance Paradox
}

\author{
Peter Maassen
}

\section{Introduction}

There is a growing pressure on universities to involve proactively in various types of competition, including national and global competitions for resources, students and staff, and the competition for academic prestige and status. This pressure is, amongst other things, exerted through national reform agendas. But how is the formal governance responsibility for determining and leading the competitive behavior of universities adapted in response to these pressures? And how does this formal governance responsibility work in practice? Answering these questions requires a focus on the institutional governance arrangements and how governance has developed over time with a changing internal and external dynamics (Maassen 2003). Strikingly, in the way these governance questions have been addressed in university practices, a paradox has emerged: The more university leaders take on and operate in line with the reform agenda's ideologies, the less effective they appear to be in realizing the reform intentions. How can such a paradox be accounted for?

This question is approached in this article in the following three steps. First, three general theories of governance are introduced. Second, having outlined the research from which the empirical data is drawn, we spell out how governance practices have developed over time taking the three perspectives on governance as the starting point. Then we discuss the governance paradox that arises from the interplay of university history and traditions, changes in the formal governance structures, the ideologies underlying university reforms, and the perspective of a prestige economy.

\section{Theories of governance - history, organization and strategic action}

A historical-institutional perspective on governance highlights how governance structures of organizations are shaped by traditions and sets of norms for what constitutes acceptable behavior. Consequently, ways of acting take on a meaning beyond their instrumental value and also delimit the scope of action for organizational members and leaders (Selznik 1966). Organizations comprise cultures and codes of meaning that make it hard to instigate governance practices that are deemed inappropriate and introduce change that goes against the 'spirit' and inherited practices (March and Olsen 1989). 
From a structural-organizational perspective the argument is that the formal structure of organizations intervenes in governance processes and creates a systematic bias, thus making some process characteristics and outputs more likely than others (Egeberg et al. 2016, 32). Formal organization structure defines who is supposed to do what, how and when through specifying role expectations attached to formal positions within the organization (Scott 2008). Three aspects of organizational structure can in particular be expected to affect governance (Egeberg et al. 2016): 1) the vertical specialization, that is, how tasks and responsibilities are distributed among organizational levels; 2 ) the horizontal specialization, that is, how tasks are divided among organizational departments and according to what principle of specialization; and 3 ) the clarity of the role expectations attached to organizational positions.

A rational actor perspective on governance will rather underline how organizational members and leaders strategically respond to competition and incentives, opportunities for attracting resources to one self or one's group, irrespectively of traditions and role expectations. The competition for resources is argued to drive actual behavior and change depends on getting the incentives right. Therefore in this perspective change is the result of strategic actions of institutional leaders and managers (Gornitzka et al. 2007).

\section{Data and methods}

The analysis of institutional governance and the factors affecting it draws on the research project on European Flagship universities. In this project it was studied how major research intensive universities (referred to as 'Flagships') interpret and use institutional autonomy internally. Comprehensive Flagships in eight European countries, that is, Austria, Belgium (Flanders), Denmark, Finland, the Netherlands, Norway, Sweden, and Switzerland, were involved in the project.

The project represents our interests in contributing to a better understanding of the universities' internal processes, including the institutional leadership's actions focused on making universities more competitive, and how these efforts have affected the internal academic life. We had a special interest in the departmental level, given that there is relatively little empirical data available on research intensive universities' internal change dynamics. The four academic areas we included in our departmental level studies were: chemistry, psychology, public health, and teacher education. In the case studies we focused on personnel policies and research management. A combination of documentary evidence and interview data from 12 Flagships from the eight involved countries were used to analyze the actual practice of governance in these two areas, both core aspects of university life. 


\section{Historical factors in university life - does history matter for university governance?}

We start the discussion of the university governance paradox by addressing the historical perspective. The reason is that the German Research University model has become the dominant template that also nowadays determines the way we interpret the university in all its functions in its national and global contexts. The origins of this University template are important for understanding the current governance paradox.

Before the period between 1815 and roughly 1850 (Turner 1971, Watson 2010) universities in Europe and elsewhere were purely teaching institutions; research was not an activity that took place within universities. Yet, within a relatively short time German universities became intensively research oriented. How did that happen and how did that affect the professorship? Also, what are the disciplinary developments that can be argued to result from this emergence of the modern research university?

In this period - in German referred to as the Vormärz Era - the traditional loyalty of professors to their university changed into the dual loyalty to the university and discipline. In the traditional institutional loyalty the professor is essentially an inspiring teacher with strong ties with his colleagues, identifying with his university and accepting his share of its teaching tasks. The second loyalty is first and foremost anchored in research and other contributions to the disciplines that emerged in this period. In the disciplinary communities the academic values are established that are connected with the new professional task of the university professor as knowledge producer and disseminator. According to Turner (1971, 158): "These values center around the struggle for reputation and recognition within the disciplinary community". The consequences of the changes at that time were that the possibilities of a university's leadership to govern the activities of its professors directly were reduced quite considerably.

The radical transformation is the result of three main factors (Turner 1971, 139). One was the Humboldtian ideology promoting Wissenschaft in the sense of the creation of new knowledge, which was regarded as the main driving force for the development of a new German society and a new citizen. The second was competition and decentralization within the Germany university system focusing very strongly on the productivity and status of the professors. And the third factor of great importance was the role of the state that took over from the universities the main responsibilities with respect to recruiting and appointing professors and in this was emphasizing the research output of the professors.

The resulting governance issue is that the professor has a contract with his/her university, which is paying for the teaching and all the university-centered functions of the professor. However, in the recruitment of professors and all tenured academic staff members as well as in their career and status advancement, the disciplinary values and criteria are more influential than institutional values and criteria. This includes the criteria that professors use to determine 
what is high academic quality and low academic quality, also in their teaching activities. As a result, in the Vormärz Era disciplinary values and criteria became more important for the academic profession than the institutional ones. This dominance has continued until today. The limited direct influence of university leaders on disciplinary settings makes it complicated and very difficult to have university governance structures that can steer, let alone control, the disciplinary activities of the university's academic staff.

\section{Do organizational structures matter for governance?}

The formal structures of universities have traditionally been referred to as the epitome of the bottom-heavy organization that is in its essence a loosely coupled organization (Weick 1976). These characteristics are structural conditions under which governance takes place. In looselycoupled organizations marked by ambiguous goals, unclear causal understandings, and actors with attention problems, participation in governance processes can be expected to be fluid. What kind of problems and solutions that are attended to in loosely-coupled organizations, such as universities, is more likely to be event driven and sensitive to fluctuations in decision makers' attention than in organizations that have clearer hierarchies and where roles and responsibilities are clearly specified (Cohen et al. 2012; March and Olsen 1976). This specific pattern of governance is recognizable in universities' approach to handling both academic and non-academic issues and topics, especially in governance processes across the vertical axis in the organization.

On the other hand the horizontal specialization has fairly structured effects on governance in the universities and this concerns the role of its basic organizational units. Departments are important for our understanding of university governance as they traditionally have organized academic work and linked universities to disciplines and professions (Clark 1960, 1972, Mintzberg 1979). In a 'classic' model of university departments (Abbott 1988, 1999), individual academic staff members are professionals who enjoy considerable autonomy over their work and depend upon public support for monopoly authority over complex problems. In the recent US literature (Brint 2002, Hearn 2007) there is a lot of emphasis on the changes around the department, implying that dramatic environmental changes have shifted the conditions of academic staff members' work and challenged the traditional model of professionalism in which the department was the core university building block.

One additional governance challenge that deserves more attention in the scholarly literature than can be given in this article has marked research and personnel management in the past two decades - a challenge rooted in the organizational additions that have been layered on to the traditional components of the organizational structure of research-intensive universities. New centres and cross-disciplinary schemes have been added to the department/faculty structure, as well as inter-university collaboration projects, and new joint organizational structures with other external partners, including private sector firms. Practically all new 
ambitions (internal or external) have implied that the structural complexity of universities has increased and by consequence also the complexity of university governance.

\section{University governance as strategic choice in competitive environments}

Next perspective concerns the ideologies underlying university reforms starting in the 1980s (Maassen 2003) that aimed at developing the university into a more competitive organization through turning it into an integrated strategic actor (Krücken and Meier 2006). Here we see some of the ideological perspectives underlying the state's governance models and the reforms initiated to change them:

1. Centralized governance: government control through a hierarchical governance relationship between state authorities and universities

2. Negotiated governance: power dynamics (network configurations)

3. Competitive governance: market evolution, that is, diversity / selection / retention (managerial niche identification).

The reforms started with efforts to move from the hierarchical centralized state model of university governance to a state supervision approach (Van Vught 1989), which implied moving towards a model that was based on negotiations among a number of core stakeholders. From the early 1990s on a third reform ideology emerged that has since been dominating national university reform agendas: competitive governance.

The basic assumption of this reform ideology is first that autonomous universities more effectively accommodate the needs of various stakeholders and the knowledge marketplace than strictly state-controlled universities, and second that the strategic organizational actorhood of autonomous universities leads to a more healthy system integration and system diversity. An important mechanism in this assumed change dynamics of universities is that professional university leadership will strategically identify a fitting 'niche' for the university. This will take place when the institutional leadership uses the enhanced institutional autonomy to strengthen the internal integration of the university, moving it from being a loosely coupled to a more tightly coupled organization.

But why are the outcomes of university reforms in general not in line with the reform intentions? One possible explanation is that national governance reforms in general have failed to do justice to the basic institutional foundations of the university. The university as an institution has been operating since the Middle Ages - and in some respects even before - and it has become the predominant institutional form for handling knowledge in societies. Taking the institutional foundation of the university into account shows the relevance of the two loyalties (to university and discipline) when it comes to understanding how they affect the 
preferred behavior and attitudes of the academic staff of the university. Another aspect is that universities cannot be changed overnight. They operate on the basis of stable principles, anchored in the ways in which university staff act, which is in accordance with fairly stable principles, based on rules of appropriate behaviour for specific roles and situations (Maassen and Olsen 2007).

Overall the impacts of post-1980 university governance reforms depend on how they match with and are absorbed by existing cultures, practices, as well as organizational and disciplinary identities (Gornitzka et al. 2007). There are many examples of quite radical reforms where the outcome was not that the university was adapted to match the intentions of the reform, but that the reform in its implementation was adapted to the university's institutional foundations. Interpreting university reform from an institutional perspective is important for understanding the university's robustness and the fact that even though the end of the university has been announced for at least 200 years, it does not seem that this end has come any closer.

What is the governance issue resulting from this lack of coupling between reform agendas' ideology and the institutional foundation of the university? The reform ideologies assume that universities can become more tightly coupled organizations with a leadership that is in control of the institution's primary production processes (education and research) as well as its external relations and partnerships. But: the university leadership has only very limited control over its institution's primary processes. A possible consequence is that the more tightly coupled the university becomes, and the more the leadership tries to control the primary processes, the greater the chance that the university loses prestige and its attractiveness for top academics and highly talented students.

\section{A prestige economy perspective on university governance}

One mechanism affecting university governance that comes to the fore with the increase of the involvement of the university in competitive arenas is what we can refer to as the 'prestige economy', which stems from the work of Sheila Slaughter and her colleagues (Rosinger et al. 2016). The prestige economy perspective is of relevance in the interpretation of the university governance paradox since it conceptualizes the impact of competitive funding on university governance. Prestige economy as a concept is rooted in the argument that some external financial resources are preferred over others, that is, those that are most attractive are the resources from competitive research funding programmes. This is especially true for research intensive universities.

In US higher education the impact of the prestige economy has created a segmentation within universities on the basis of the status given to some external revenues (high prestige competitive research funding) at the expense of others (consultancy income, tuition fee and 
other education income). High status, derived from a competitive logic and dependent on the success in the external competition for high prestige research funding, means for a department reduction in educational tasks and activities (especially at the undergraduate level), more internal resources, more tenured positions, and more control over resources. Low status, related to an administrative logic and the result of a lack of success in the external competition for high prestige research funding, implies for a department an increased teaching burden. This is a consequence of the authority of the institutional administration in educational matters and its abilities to govern the university's education activities through the allocation of resources and the control over the academic positions of a department. This means in practice that in high status departments the academics themselves are in control over the external high prestige research funding for which they competed successfully, while in low status departments the academics are required to spend most of their professional time on educational activities without any control over the tuition fees and other sources of educational income resulting from their academic teaching efforts.

How does the prestige economy work in European universities? A diverging trend is that in Europe still a large part of the educational costs of universities are publicly funded by the government through a basic grant. In most countries tuition fees only form a small segment of the income of the (Continental) European university. Strikingly, some countries (Germany, Denmark, Finland, Norway, and Sweden) are still not allowing their universities to charge tuition fees to national and EU students. Basic grants have been relatively stable and cover between 50 and $90 \%$ of the annual budgets of the universities, while in the USA they dropped in most states below 15\%. But also in universities in Continental Europe, even though the basic grants are still relatively stable, external research funding reflects high prestige and educational income low prestige.

What this means is that also in Europe the governance of educational activities within universities is more and more dominated by the administration of the institution. However, unlike the situation in the USA, the governance realities in European universities do not allow the administration to fully control and redistribute the university's (educational) income. Therefore the steering of educational activities in European universities takes places through a growing density of procedures and regulations, to a large extent developed and determined by the institutional administration.

A competitive logic has also emerged in European universities in regard to the external funding of research. As the data from the Flagship research project shows, there is a prestige ranking of external research funding resources with the European Research Council (ERC) and national excellence schemes ranked highest, and consultancy projects ranked lowest. At the same time, there are no uniform prestige economy trends in the governance of European universities, rather major differences between countries. Unlike the situation in US universities, there is no segmentation among basic units, such as departments, in European universities, but instead 
growing differences among individual academic staff members, for example, with respect to their administrative autonomy, and their teaching obligations.

The governance issue resulting from the impact of the prestige economy is that university leadership prefers maximizing prestige and not unconditionally maximizing financial income. This is a result of prestige being a more important resource for research intensive universities than income per se. As a result, university leaders aim at combining greater control over education and low prestige research activities with less control over high prestige research activities. We have seen in all universities involved in the Flagship project that academic staff members who are successful in the competition for high prestige external research funding manage to negotiate a very different administrative and management reality than those who are not successful.

\section{The university governance paradox - the interplay of history, structure and competition}

What then is the current university governance paradox emerging from the theories and governance issues discussed above? Overall the term "paradox" refers to the starting point that current reform agendas want universities to become more competitive and more responsive to society's needs. This implies, amongst other things, the aim to creating tighter couplings among institutional and disciplinary settings, to be realized by the university leadership that should become more professional in order to be able to manage this task successfully, that is, it should become more hierarchical, more strategic, more executive, and supported by a professional administration that operates in a more standardized, specialized, formalized way. However, as discussed above, in practice university leaders and administrators have only limited direct control over the substantive academic dimensions of the primary processes within their university, and no control over disciplinary settings.

This leads to a paradox in university governance practices, in the sense that the more university leaders operate in line with university reform agendas' ideologies, the less effective they seem to be in realizing some of the main the reform intentions. This concerns especially the intention of stimulating the development of clear institutional profiles, and thereby creating a (more) diversified higher education system. In essence the paradox has to do with the assumption that professional university leadership will be able to control the development of the academic activities of its staff more directly resulting in strategic choices about which profile to develop. However, in the university practice the more the leadership manages to control the academic activities of its staff, the less likely the staff be able to compete successfully in the national and international competition for research funding, and highly talented PhD students and postdocs. This is a consequence of the level of autonomy the most productive staff requires for determining where and how to compete. 
A common starting point in the professionalization of university leadership is the emphasis on a leadership and management approach that can be referred to as 'bottom-line management'. This implies a 'one-size-fits-all' management approach, which includes homogeneous productivity and output targets for all, and represents the attempt to create a tighter coupling of academic units and staff to institutional leadership and management ('organizational actorhood'). However, in order to realize the main strategic goal of a flagship university, that is, to be a high status, leading research intensive university, highly productive professors should be exempt from bottom-line management. These professors should be able to negotiate a looser coupling to institutional management, resulting in more autonomy for managing their research activities in a way that they feel fits these activities best.

Some flagship universities involved in our project have gradually moved beyond 'bottom-line management'. Their institutional leadership is looking for more flexible, more horizontal, more academically anchored ways in making their leadership decisions at all levels. Instead of having, for example, homogeneous productivity targets and standardized ways in which staff performance is assessed and evaluated ('management by objectives'), they are in the process of developing a 'management by assessment and judgment' approach.

We can also see this kind of management by assessment and judgment emerging at the national level, for example, in the Netherlands. In 2015 there were intense student and staff protests at the University of Amsterdam, followed by protests at other Dutch universities. A major criticism was that the university leadership was too much focused on economic results, and not enough on academic development. In the end the Dutch government - first and foremost the Dutch Minister of Education - agreed with some elements of the protests, and a policy proposal was developing intended to shift authority in the Dutch universities from the executive board and the institutional leadership in a number of respects back to students and staff, including areas such as personal policies and budget decisions. Within this 'living autonomy' context, the University of Amsterdam has set up an institutional committee that has developed three proposals for making the university more democratic and less centralized. Staff and students of the university have voted on these proposals in referendum held December 2016.

\section{Conclusions}

For interpreting the intra-institutional governance dynamics at the involved European flagship universities in a valid way various factors have to be taken into account. It is, for example, of importance to understand how the governance relationship between leadership and staff (plus students) at research intensive universities is affected by a number of basic institutional characteristics, including: 
a. The formal legal status of the university: in some Continental European countries universities are still state-owned, that is, part of the state structure, even though in most countries the universities have become self-owned public corporations, or owned by private foundations.

b. The variations in institutional traditions and cultures, national, regional and institutional settings (including the economic institutional foundation), disciplinary fields that are represented in the institution, etc.

c. The inter-university variations in the levels and nature of success in competition for external funding.

d. The variations in institutional personnel policies and practices.

e. The actor dimension, especially when it comes to the personalities and backgrounds of the main governance actors within the university, as well as nationally.

Variations in these basic characteristics form the foundation for growing differences among research intensive universities, but also within universities, when it comes to institutional governance structures and practices. Also at the departmental level there are many differences among and within universities in how governance is organized and structured, as well as in how governance challenges are handled.

A number of research intensive universities have overall allowed for a growing level of flexibility in their internal governance practices. This implies, for example, that one can find throughout the institution various examples of coupling, that is, looser or tighter coupling, between institutional leadership and academic groups/units with various kinds of impact on the involved individual academic staff. It can be concluded that in these institutions a growing understanding of the factors that affect academic productivity is emerging, and how this productivity can be managed best, moving away from the bottom-line management approach.

Fourth, overall there are many examples in the involved universities of effective couplings of university leadership and the institutional professoriate, with interactions that are an expression of a more flexible approach to university governance. However, there is still a mismatch between the increasingly flexible leadership and university academics on the one side, and the professional university administration on the other side. The following quote from one of the interviewees in the project summarizes a main observation in this: "in my institution the university administration has become much more professional but at the same time less effective and supportive". This highlights the struggles that universities are dealing with in the new competitive era where the governance approaches they are promoted to use do not necessarily lead to the outcomes expected.

\section{References}


Abbott, A. (1988). The System of Professions. An Essay on the Division of Expert Labor. Chicago: University of Chicago Press.

Abbott, A. (1999). Department \& Discipline: Chicago Sociology at One Hundred. Chicago: University of Chicago Press.

Brint, S. (2002). The Future of the City of Intellect: The Changing American University. Stanford: Stanford University Press.

Clark, B.R. (1960), 'The 'Cooling-Out' Function in Higher Education,' The American Journal of Sociology, 65(6), 569-76.

Clark, B.R. (1972). 'The Organizational Saga in Higher Education', Administrative Science Quarterly, XVII, 178-184.

Egeberg, M, Å. Gornitzka and J. Trondal (2016). Organization Theory, In C. Ansell and J. Torfing (eds.) Handbook on Theories of Governance. Cheltenham: Edward Elgar Publishing, 32-45.

Gornitzka, Å., P. Maassen, J.P. Olsen and B. Stensaker (2007). "Europe of Knowledge" Search for a New Pact, in: P. Maassen and J.P. Olsen (eds) University Dynamics and European Integration. Dordrecht: Springer, 181-214.

Hearn, J.C. (2007). Sociological Studies of Academic Departments, in: P.J. Gumport (ed.) Sociology of Higher Education. Contributions and Their Contexts. Baltimore: The Johns Hopkins University Press, 222-266.

Krücken, G. and F. Meier (2006). Turning the University into an Organizational Actor, in: G. Drori, J. Meyer and H. Hwang (eds.), Globalization and Organization: World Society and Organizational Change. Oxford, Oxford University Press.

Maassen, P. (2003). Shifts in Governance Arrangements: An Interpretation of the Introduction of New Management Structures in Higher Education, in: A. Amaral, V.L. Meek, and I.M. Larsen (eds.), The Higher Education Managerial Revolution? Dordrecht: Kluwer Academic Publishers, 31-53.

Maassen, P. and J.P. Olsen (eds) (2007). University Dynamics and European Integration. Dordrecht: Springer.

March, J.G. and J.P. Olsen (1983). 'The new institutionalism: Organizational factors in political life', American Political Science Review, 78 (3), 734-749.

Mintzberg, H. (1979). The Structuring of Organizations: A Synthesis of the Research, Englewood Cliffs, NJ: Prentice Hall. 
Rosinger, K.O., B.J. Taylor, L. Coco, and S. Slaughter (2016). Organizational Segmentation and the Prestige Economy: Deprofessionalization in High- and Low-Resource Departments. The Journal of Higher Education, 87(1), 27-54.

Scott, W.R. (2008). Institutions and Organizations, Thousand Oaks, CA: Sage

Selznick, P. (1966). Leadership in Administration, New York: Harper \& Row.

Simon, H.A. (1965). Administrative Behavior, New York: Free Press.

Turner, R.S. (1971). 'The Growth of Professorial Research in Prussia, 1818 to 1848 - Causes and Context.' Historical Studies in the Physical Sciences, 3, 137-182.

Van Vught, F.A. (1989). Governmental Strategies and Innovation in Higher Education. London: Jessica Kingsley.

Watson, P. (2010). The German Genius. Europe's third renaissance, the second scientific revolution, and the twentieth century. London: Simon \& Schuster.

Weick, K.E. (1976). 'Educational organizations as loosely coupled systems.' Administrative Science Quarterly, 21(1), 1-19. 